\title{
Morphine interaction with prasugrel: a double-blind, cross-over trial in healthy volunteers
}

\author{
Eva-Luise Hobl ${ }^{1}$ - Birgit Reiter ${ }^{2}$ - Christian Schoergenhofer ${ }^{1} \cdot$ Michael Schwameis $^{1}$. \\ Ulla Derhaschnig ${ }^{1}$ Irene Marthe Lang ${ }^{3} \cdot$ Thomas Stimpfl $^{2} \cdot$ Bernd Jilma $^{1}$
}

Received: 26 August 2015/Accepted: 15 October 2015/Published online: 22 October 2015

(c) The Author(s) 2015. This article is published with open access at Springerlink.com

\begin{abstract}
Background Morphine decreases the concentrations and effects of clopidogrel, which could lead to treatment failure in myocardial infarction.

Objectives To clarify whether more potent $\mathrm{P}_{2} \mathrm{Y}_{12}$-inhibitors may provide an effective alternative, we examined drug-drug interactions between morphine and prasugrel.

Methods Twelve healthy volunteers received $60 \mathrm{mg}$ prasugrel with placebo or $5 \mathrm{mg}$ morphine intravenously in a randomized, double-blind, placebo-controlled, cross-over trial. Pharmacokinetics were determined by liquid chromatography tandem mass spectrometry, and prasugrel effects were measured by platelet function tests.

Results Morphine neither diminished total drug exposure (AUC), which was the primary endpoint, nor significantly delayed drug absorption of prasugrel. However, morphine reduced maximal plasma concentrations $\left(C_{\max }\right)$ of prasugrel active metabolite by $31 \%(p=0.019)$. Morphine slightly, but not significantly, delayed the onset of maximal inhibition of platelet plug formation under high shear rates (30 vs. $20 \mathrm{~min}$ ). Whole blood aggregation was not influenced.
\end{abstract}

T. Stimpfl and B. Jilma contributed equally.

Eva-Luise Hobl

eva-luise.hobl@meduniwien.ac.at

Bernd Jilma

bernd.jilma@meduniwien.ac.at

1 Department of Clinical Pharmacology, Medical University of Vienna, Waehringer Guertel 18-20, 1090 Vienna, Austria

2 Clinical Institute of Medical and Chemical Laboratory Diagnostics, Medical University of Vienna, Vienna, Austria

3 Department of Internal Medicine II, Division of Cardiology, Medical University of Vienna, Vienna, Austria
Conclusions Although morphine significantly decreases the maximal plasma concentrations of prasugrel active metabolite, it does not diminish its effects on platelets to a clinically relevant degree in healthy volunteers. However, it should be considered that the observed decrease in $C_{\max }$ of prasugrel active metabolite caused by morphine co-administration may gain relevance in STEMI patients. Clinical Trial Registration: NCT01369186, EUDRA-CT\#: 2010-023761-22.

Keywords Drug interactions - Morphine - Platelet function tests · Prasugrel · Vasodilator-stimulated phosphoprotein

\section{Introduction}

Coronary heart disease is one of the most common causes of death worldwide and numerous publications document the permanently increasing research activity in the field of acute coronary syndromes (ACS) [1-11].

As adenosine-5'-diphosphate (ADP) is one of the primary mediators for platelet aggregation, the administration of $\mathrm{P}_{2} \mathrm{Y}_{12}$-inhibitors in combination with aspirin is a mainstay in the treatment of patients with acute coronary syndromes [12].

In contrast to the extensive evidence that ADP inhibitors are beneficial in patients suffering from myocardial infarction, such data from randomized controlled trials are lacking for morphine. Interestingly, the use of morphine is associated with higher mortality in patients with non-ST-segment elevation ACS [13]. While this is not a causal proof, there may be a biologically plausible cause-effect relationship: opiates inhibit gastric emptying which delays drug absorption and may decrease peak plasma levels of peroral drugs [14]. 
Indeed, a recent randomized, controlled trial demonstrated that morphine lowers the plasma levels of clopidogrel as well as its antiplatelet effects [15], which could lead to treatment failure in susceptible patients.

It can be hypothesized that more potent $\mathrm{P} 2 \mathrm{Y}_{12}$-inhibitors may provide a more effective alternative to clopidogrel when morphine is given, but their interaction with morphine has to be evaluated. Whereas the prodrug clopidogrel is converted into its active metabolite by cytochrome $\mathrm{P} 450$ enzymes in two steps [16, 17], prasugrel is rapidly hydrolyzed by esterases to an intermediate metabolite and requires only one further CYP-dependent oxidation step to generate its active compound [16-18]. This produces more active metabolite [19], reduces the variability in response between patients and leads to a more consistent and stronger inhibition of platelets [20-24]. We therefore hypothesized that the observed negative interaction between morphine and clopidogrel [15] may be partially mitigated when prasugrel is used instead of clopidogrel, and conducted this randomized controlled trial to investigate the effect of morphine on the pharmacodynamics and pharmacokinetics of prasugrel.

\section{Methods}

\section{Experimental design and blood collection}

A double-blind, block-randomized, placebo-controlled, cross-over trial was conducted in accordance with good clinical practice guidelines and the Declaration of Helsinki to evaluate the effects of morphine on the intestinal resorption, pharmacokinetics and pharmacodynamics of prasugrel. The study was approved by the Ethics Committee of the Medical University of Vienna and the Austrian National Competent Authority and registered at ClinicalTrials.gov (NCT01369186); written informed consent was obtained from all healthy subjects $(n=12)$.

Key inclusion criteria were: $\geq 18$ years of age; nonpregnant; the ability to comprehend the full nature and purpose of the study. Key exclusion criteria were: intake of non-steroidal anti-inflammatory drugs or platelet inhibitors; known coagulation disorders; relevant impairment of renal or hepatic function; chronic infectious diseases (HIV, hepatitis B and C); clinically relevant abnormal laboratory values; and contraindications for prasugrel or morphine.

Secretaries conducted randomization by www.randomi zation.com, and prepared individually sealed opaque envelops. Morphine (5 mg i.v. bolus; Vendal, G.L. Pharma, Lannach, Austria) or placebo $(0.9 \% \mathrm{NaCl})$ were prepared by unblinded pharmacists and injected by blinded physicians. A minimum wash-out period of 14 days was chosen (Fig. 1) because it exceeds platelet survival in vivo and because the effect of $\mathrm{P}_{2} \mathrm{Y}_{12}$-inhibition diminishes within 5 days [25].

After an overnight fast, a loading dose of $60 \mathrm{mg}$ prasugrel (Efient, Eli Lilly, Vienna, Austria) was administered with $250 \mathrm{~mL}$ tap water immediately after the injection of placebo or morphine. No food, drink or tobacco was permitted for $4 \mathrm{~h}$.

Blood sampling times for pharmacodynamic and pharmacokinetic evaluations after study drug administration were $5,10,15,20,30,45,60,75,90,120,180,240$ and 360 min (Figs. 2, 3 and 4). Blood was collected using an i.v. catheter after drawing a waste sample. The analysts were also blinded with regard to the sequence of periods.

\section{Assessment of pharmacokinetics and pharmacodynamics}

Prasugrel effects were measured with the following assays: multiple electrode aggregometry [26], where the intercept of the individual down-slope and the plateau phase was plotted graphically for the area under the curve (AUC) to estimate the onset of the maximum effect, and with the platelet function analyzer under high shear rates [27], where the onset of the maximum effect was defined as the first of three consecutive measurements of $>300 \mathrm{~s}$.

To determine the vasodilator-stimulated phosphoprotein (VASP) phosphorylation state of the whole blood, a standardized flow cytometric assay (PLT VASP, BioCytex, Marseille, France) was used, initially described by Schwarz et al. [28]. Blood samples collected in $3.8 \%$ sodium citrate (BD Vacutainer, Becton-Dickinson, Schwechat, Austria) were incubated in vitro with adenosine diphosphate and/or prostaglandin E1 (PGE1) before fixation. For the presentation of data, we used the median fluorescence intensity (MFI) as described earlier [26].

Whole blood aggregation was determined by an impedance aggregometer (Multiple Platelet Function Analyzer/ Multiplate Analyzer, Roche, Vienna, Austria). As recommended by the manufacturer, we used hirudin as an anticoagulant. When activated in the test cartridge, platelets attach onto metal electrodes and aggregate, resulting in increased electrical resistance. This change in impedance is recorded for $6 \mathrm{~min}$ and is proportional to platelet aggregation. Blood was diluted with saline solution $(0.9 \%)$ at a 1:1 ratio and incubated for $3 \mathrm{~min}$. After stirring at $37^{\circ} \mathrm{C}$, analyses were performed using the agonists $\operatorname{ADP}(6.4 \mu \mathrm{M})$ and PGE1 $(9.4 \mu \mathrm{M})$ (Dynabyte Medical, Munich, Germany). Results were expressed as areas under the curve of the aggregation tracing (AUC). Following the recommendations of the manufacturer and for simpler presentation purposes, we expressed the results as units (U) [29].

Platelet plug formation under high shear rates $\left(5000-6000 \mathrm{~s}^{-1}\right)$ was quantified by the platelet function 


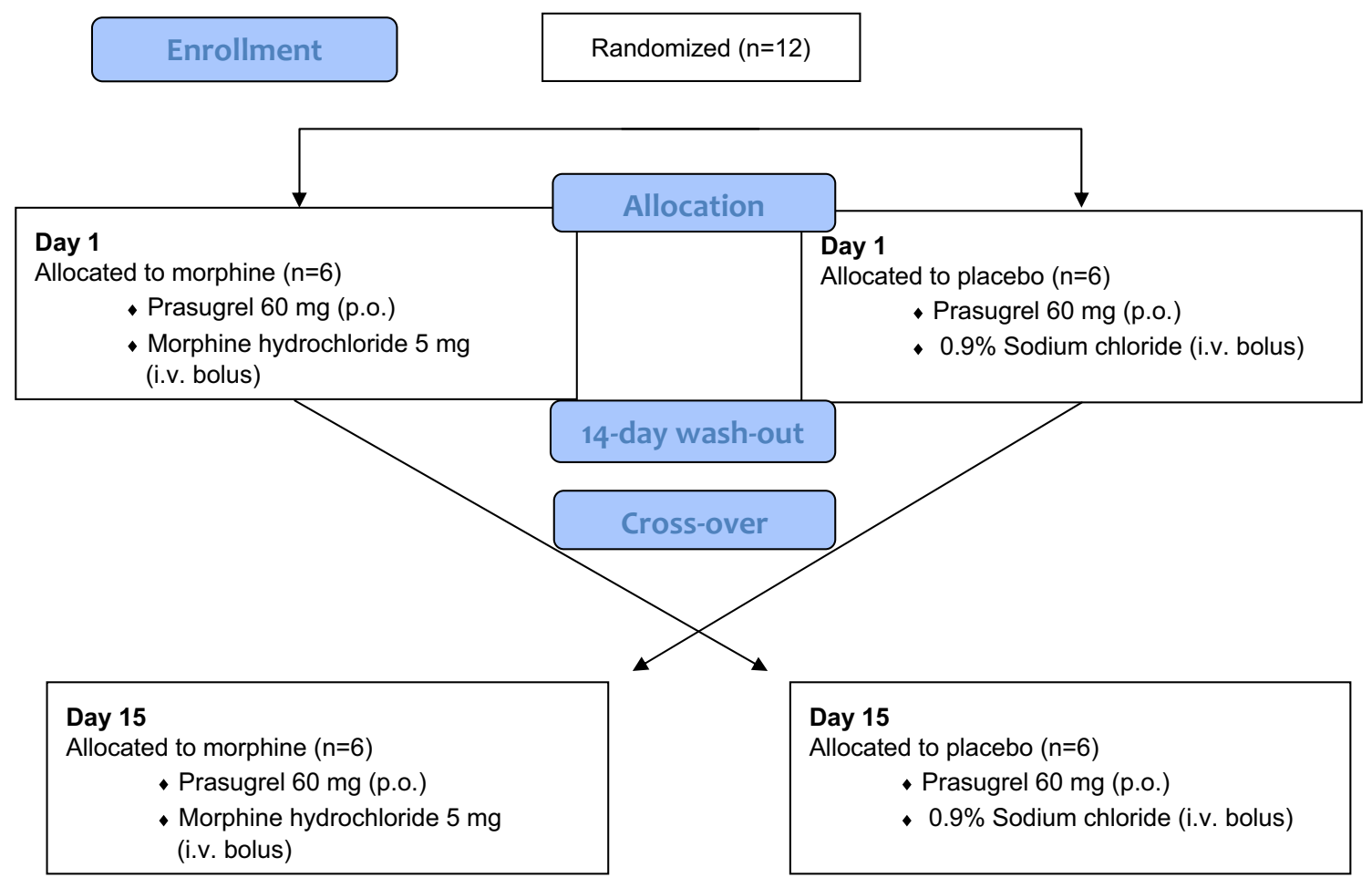

Fig. 1 Schematic of trial design

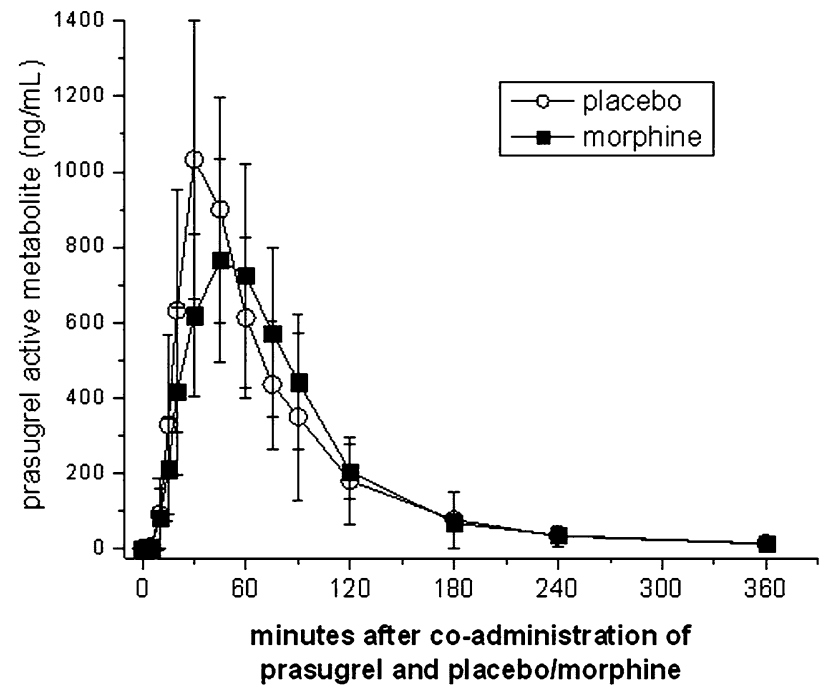

Fig. 2 Morphine lowers maximum plasma concentrations of prasugrel active metabolite. Healthy volunteers $(n=12)$ received a $60 \mathrm{mg}$ loading dose concomitantly with a placebo or $5 \mathrm{mg}$ morphine. Data present means $\pm 95 \%$ CI. $p$ values for the comparisons between placebo and morphine: AUC 0.239; $C_{\max } 0.019 * ; T_{\max } 0.798$ (*indicates significance)

analyzer (PFA-100, Siemens Healthcare Diagnostics, Vienna, Austria). Blood samples were collected in $3.8 \%$ sodium citrate. The PFA-100 measures the time required for occlusion of the aperture by platelet plugs, which is defined as closure time (CT). The maximum duration of a measurement is $300 \mathrm{~s}$. The instrument aspirates a blood sample under constant vacuum from the sample reservoir through a capillary and a microscopic aperture $(147 \mathrm{~lm})$ cut into the membrane, which leads to high shear induced platelet plug formation. The membrane is coated with collagen/adenosine diphosphate (CADP). The P2Y-innovance cartridge, which is more sensitive to prasugrel, was used to follow the evolution of platelet inhibition under high shear rates over time. In addition, the CADP-CT was measured at baseline and after $6 \mathrm{~h}$ (reference range 65-120 s) [30, 31].

Plasma concentrations of prasugrel active metabolite were determined by liquid chromatography tandem mass spectrometry. Blood samples $(6 \mathrm{~mL})$ were collected in precooled EDTA tubes (BD Vacutainer, Becton-Dickinson, Schwechat, Austria). The blood samples were gently inverted and centrifuged within $30 \mathrm{~min}$ at $1400 \times g\left(15 \mathrm{~min}, 2-8^{\circ} \mathrm{C}\right)$ to separate the plasma. Aliquots were stored at $-80{ }^{\circ} \mathrm{C}$ and analyzed within 3 months. The applied system consisted of a Symbiosis ALIAS chromatographic system (Spark Holland B.V., Emmen, Netherlands) and an AB Sciex detector (QTRAP 5500, AB Sciex, Framingham, MA, USA). A published procedure [32] was modified to perform the analyses. 


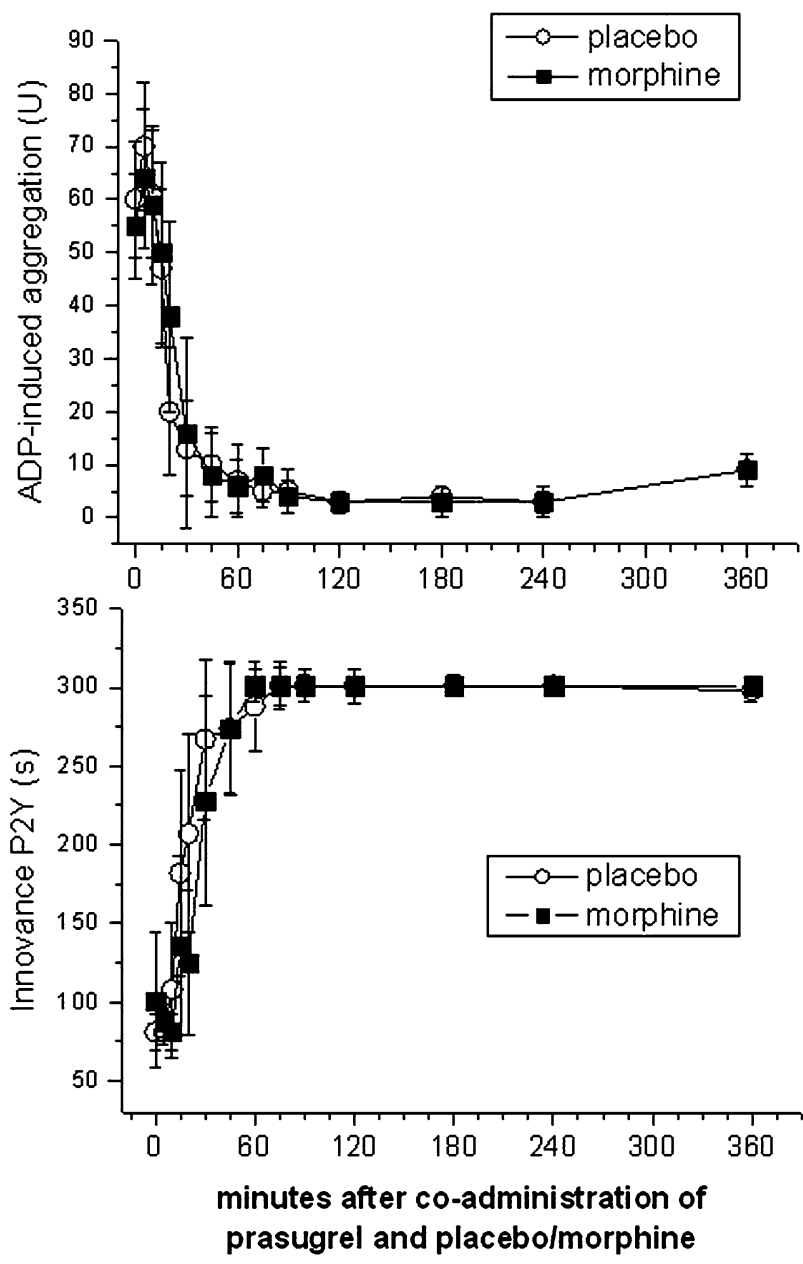

Fig. 3 Morphine does not retard or decrease prasugrel effects to a clinically relevant degree. Adenosine diphosphate-induced aggregation was measured by whole blood aggregometry $(n=12)$ and with the P2Y-cartridge of the platelet function analyzer $(n=12)$. Since significance is lost after correction for multiple comparisons, at none of the time points there was a significant difference between placebo and morphine. Data present means $\pm 95 \% \mathrm{CI}$

\section{Statistical analysis}

The sample size calculation was based on our previously performed drug-drug interaction trial with clopidogrel [15]. Assuming a drop-out rate of $10 \%$, we calculated that we would need 12 subjects in a cross-over design to achieve $90 \%$ power $(\alpha=0.05)$.

Pharmacokinetic calculations were made using Kinetica $200{ }^{\circledR}$ version 3.0 (InnaPhase Corporation, Philadelphia, Pennsylvania). As usual for drug interaction studies, the primary pharmacokinetic outcome variable was the AUC of prasugrel active metabolite; all other comparisons were considered secondary.

Data are presented as means for demographic data, and medians for outcome variables in the text. Changes in all outcome variables were compared by non-parametric
Wilcoxon signed-rank tests, accounting for the skewed distributions of the measurements. To assess the robustness of results, a mixed-model was fitted to test for period and carry-over effects for the outcome variables, which showed a significant effect on these analyses.

Statistical calculations were performed using commercially available software (IBM SPSS Statistics ${ }^{\circledR}$, Version 20 , and $\mathrm{SAS}^{\circledR}$, Version 9.3). In all cases, two-sided $p$ values $\leq 0.05$ were considered significant.

\section{Results}

\section{Demographic characteristics of subjects and adverse events}

Healthy volunteers (seven males, five females; 11 Caucasian, one Asian) were $30 \pm 10$ years of age, had $69 \pm 11 \mathrm{~kg}$, and a body mass index of $23 \pm 3 \mathrm{~kg} / \mathrm{m}^{2}$. No clinically relevant adverse events were observed after morphine injection, in particular no vomiting occurred.

\section{Pharmacokinetics}

Morphine did not significantly reduce the total exposure as measured by the $\mathrm{AUC}_{0-\mathrm{n}}(69,573$ vs. $65,991 \mathrm{ng} \times \mathrm{h} / \mathrm{mL}$, $p=0.239$ ), which was the primary study endpoint; i.e., the mean intra-individual difference was only $5 \%$. Morphine injection did not influence the time of maximal plasma concentrations of prasugrel active metabolite (30 vs. $38 \mathrm{~min}, p=0.798$ ), corresponding to a mean intra-individual difference of only $1 \mathrm{~min}$. Similarly, However, morphine reduced the $C_{\max }$ of prasugrel active metabolite by $31 \%$ from 1388 to $951 \mathrm{ng} / \mathrm{mL}(p=0.019)$ (Table 1; Fig. 2).

\section{Pharmacodynamics}

Whole blood aggregation was not influenced by morphine co-administration, showing maximum inhibition on average 30-45 min after prasugrel intake (Fig. 3). Only one subject in each period needed 60-75 min to reach near maximal platelet aggregation.

Co-administration of morphine slightly delayed the maximal inhibition of platelet plug formation under high shear rates (30 vs. $20 \mathrm{~min}$ ), but significance is lost after correction for multiple comparisons (Fig. 3).

No differences in the VASP phosphorylation state (Fig. 4a) and in the conventional collagen/ADP induced closure times (CADP-CT) (Fig. 4b) were observed between periods $6 \mathrm{~h}$ after morphine injection.

In general, prasugrel reduced the median platelet reactivity index in the VASP assay within $6 \mathrm{~h}$ from a median of 
A

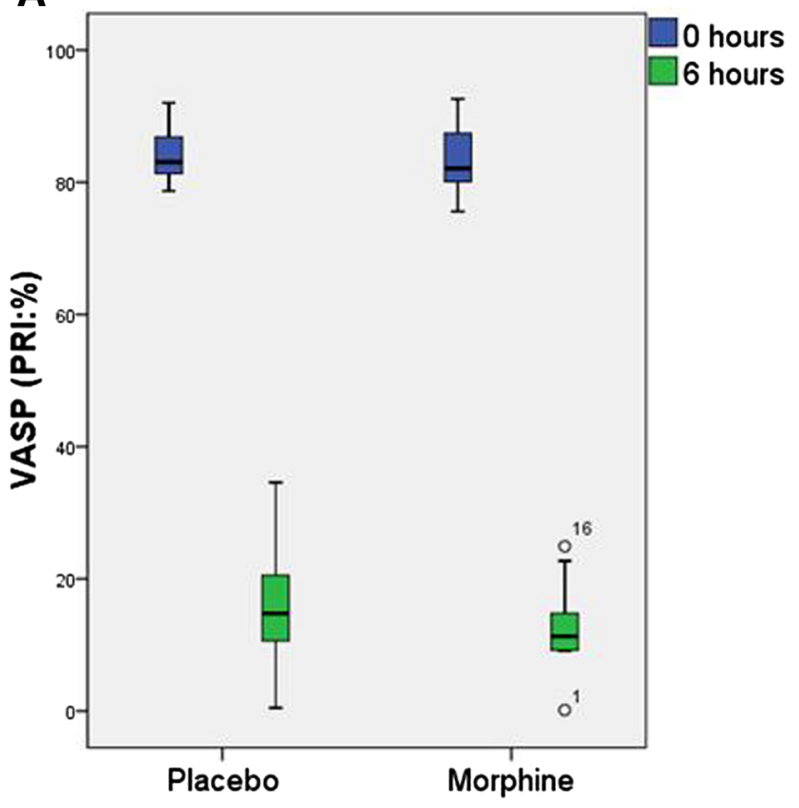

Fig. 4 Morphine does not blunt prasugrel effects. Box-and whisker plot of the vasodilator-stimulated phosphoprotein (VASP) phosphorylation (a) and the collagen adenosine diphosphate closure time (CADP-CT) (b) 0 and $6 \mathrm{~h}$ after co-administration of prasugrel and
B

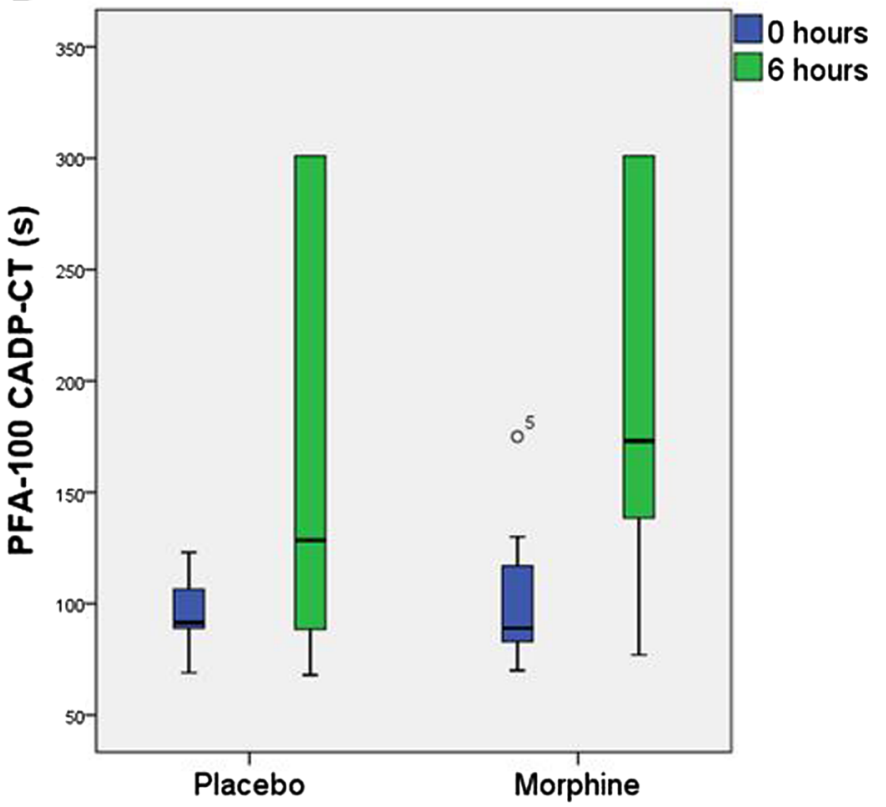

placebo/morphine. VASP phosphorylation was measured by flowcytometry $(n=12)$ and the CADP-CT with the platelet function analyzer $(n=12)$. Data present medians with 25 th and 75 th percentiles (minimum and maximum)
Table 1 Pharmacokinetic parameters of prasugrel active metabolite after a loading dose of $60 \mathrm{mg}$

\begin{tabular}{llll}
\hline Parameter & Placebo & Morphine & $p$ value \\
\hline $\mathrm{AUC}_{0-n}(\mathrm{ng} \times \mathrm{h} / \mathrm{mL})$ & $69,573(58,898-92,962)$ & $65,991(50,216-88,390)$ & 0.239 \\
$C_{\max }(\mathrm{ng} / \mathrm{mL})$ & $1388(1116-1507)$ & $951(821-1106)$ & 0.019 \\
$T_{\max }(\mathrm{min})$ & $30(30-45)$ & $38(30-60)$ & 0.798 \\
\hline
\end{tabular}

Values are medians ( \pm interquartile range); $n=12$
83 to $15 \%$ under placebo, and from 82 to $11 \%$ after morphine (for both periods: $p<0.001$, Fig. 4a).

Prasugrel intake prolonged the CADP-CT $6 \mathrm{~h}$ after intake from a median of 92-129 s under placebo and from 89 to $173 \mathrm{~s}$ when morphine was co-administered (for both periods: $p<0.001$, Fig. 4b).

No significant carry-over or period effects were observed for any of the outcome parameters.

\section{Discussion}

As prasugrel is a more potent $\mathrm{P} 2 \mathrm{Y}_{12}$-inhibitor than clopidogrel $[20,21]$ we hypothesized that it has the potential to overcome the pharmacodynamic problems of the recently described clopidogrel-morphine interaction [15] and characterized the PK/PD interaction between morphine and prasugrel.

Morphine did not reduce the total drug exposure as measured by the $\mathrm{AUC}_{0-\mathrm{n}}$, which was the primary study endpoint (Table 1; Fig. 2). A $25 \%$ change in AUC is considered a mild to moderate interaction according to the classification of the US Food and Drug Administration [33]. Our trial provided a power of $100 \%$ to exclude even such a mild interaction.

Similarly, morphine injection did not retard the $T_{\max }$ of the prasugrel active metabolite (Table 1; Fig. 2), although we achieved a power of $92 \%$ to detect a $1 \mathrm{~h}$ delay. This is in contrast to an average $2 \mathrm{~h}$ delay in the $T_{\max }$ of clopidogrel active metabolite after morphine injection [15]. However, morphine co-administration reduced the maximum plasma concentrations of prasugrel active metabolite by $31 \%$ (with a power of $92 \%$ ) (Table 1; Fig. 2). This could be clinically relevant if morphine reduced the pharmacodynamic effects of prasugrel. Even though co-administration of morphine resulted in a 10 min delay in reaching maximal inhibition of platelet plug formation under high shear rates (30 vs. $20 \mathrm{~min}$ ), significance is lost after correction for multiple comparisons. Prasugrel maximally inhibited platelet function 30-45 min after intake in both treatment periods (Fig. 3). 
In addition, the other platelet function tests such as whole blood aggregation, the VASP phosphorylation state or collagen/ADP induced closure times were not influenced by morphine (Figs. 3, 4). As all platelet assays consistently refute a significant impact of morphine on prasugrel effects, we were not able to prove a pharmacodynamic interaction of morphine with a $60 \mathrm{mg}$ loading dose of prasugrel. The currently authorized loading dose of $60 \mathrm{mg}$ prasugrel appears adequate to inhibit platelet function (Figs. 3, 4) in healthy volunteers, even when the maximal plasma concentrations of prasugrel active metabolite are reduced by $\sim 30 \%$ (Table 1 ; Fig. 2 ).

The active metabolites of prasugrel and clopidogrel have comparable anti-platelet activity in vitro. Hence, the higher in vivo potency of prasugrel reflects the more efficient generation of its active metabolite [34]. This is also demonstrated by the current pharmacokinetic data, which show that maximal plasma concentrations and exposure to the active metabolite of prasugrel (Table 1) are severalfold higher than that of clopidogrel [15] despite the tenfold higher clopidogrel loading dose.

One limitation of the current randomized trial is the investigation of healthy volunteers rather than STEMI patients, whose gastrointestinal absorption may be further compromised, e.g., by reduced splanchnic blood flow [35]. However, our cross-over design is considered most adequate for the detection of drug-drug interactions [33]. The resulting low intra-individual variability in such a cross-over design yields exclusively high power to exclude even mild interactions (100\% power for AUC) in a relatively limited sample size.

In conclusion, morphine co-administration moderately decreases the maximal plasma concentrations of prasugrel active metabolite but does not inhibit its effects on platelets to a clinically relevant degree in healthy volunteers.

Therefore, a $60 \mathrm{mg}$ loading dose of prasugrel seems to be effective when morphine is given, but it should be considered that the observed changes in the maximum plasma concentrations of prasugrel active metabolite caused by morphine co-administration may gain relevance in STEMI patients.

Acknowledgments Dr. Christa Firbas, Christa Drucker, Sabine Schranz, Karin Petroczi and Kurt Jiran are acknowledged for their assistance.

\section{Compliance with ethical standards}

Conflict of interest This work was supported by grant SFB-54 (P04) by the Austrian Science Funds (to BJ; for study conduct) and by the Medical-Scientific Fund of the Mayor of Vienna (15028 for analysis of prasugrel pharmacokinetics). The authors have no other conflicts of interest to report.

Open Access This article is distributed under the terms of the Creative Commons Attribution 4.0 International License (http:// creativecommons.org/licenses/by/4.0/), which permits unrestricted use, distribution, and reproduction in any medium, provided you give appropriate credit to the original author(s) and the source, provide a link to the Creative Commons license, and indicate if changes were made.

\section{References}

1. Wohrle J, Bertrand B, Sondergaard L, Turner M, Scholtz W, Ibrahim R, Bourlon F (2012) PFO closuRE and CryptogenIc StrokE (PRECISE) registry: a multi-center, international registry. Clinical research in cardiology: official journal of the German Cardiac Society. 101:787-793. doi:10.1007/s00392-012-0458-9

2. Clever YP, Cremers B, von Scheidt W, Bohm M, Speck U, Scheller B (2014) Compassionate use of a paclitaxel coated balloon in patients with refractory recurrent coronary in-stent restenosis. Clin Res Cardiol Off J Ger Card Soc 103:21-27. doi:10.1007/s00392-013-0617-7

3. Budzynski J, Kozinski M, Klopocka M, Kubica JM, Kubica J (2014) Clinical significance of Helicobacter pylori infection in patients with acute coronary syndromes: an overview of current evidence. Clin Res Cardiol Off J Ger Card Soc 103:855-886. doi:10.1007/s00392-014-0720-4

4. de Waha S, Eitel I, Desch S, Fuernau G, Lurz P, Urban D, Schuler G, Thiele H (2015) Intravenous morphine administration and reperfusion success in ST-elevation myocardial infarction: insights from cardiac magnetic resonance imaging. Clin Res Cardiol Off J Ger Card Soc 104:727-734. doi:10.1007/s00392015-0835-2

5. Gremmel T, Fruhwirth K, Kopp CW, Kaider A, Steiner S, Bakchoul T, Sachs UJ, Koppensteiner R, Panzer S (2012) Frequency of heparin/platelet factor 4-dependent platelet antibodies in patients undergoing angioplasty and stenting for cardiovascular disease and their role for on-clopidogrel platelet reactivity. Clin Res Cardiol Off J Ger Card Soc 101:445-452. doi:10.1007/ s00392-011-0411-3

6. Stark R, Kirchberger I, Hunger M, Heier M, Leidl R, von Scheidt W, Meisinger C, Holle R (2014) Improving care of post-infarct patients: effects of disease management programmes and care according to international guidelines. Clin Res Cardiol Off J Ger Card Soc 103:237-245. doi:10.1007/s00392-013-0643-5

7. Liosis S, Bauer T, Schiele R, Gohlke H, Gottwik M, Katus H, Sabin G, Zahn R, Schneider S, Rauch B, Senges J, Zeymer U (2013) Predictors of 1-year mortality in patients with contemporary guideline-adherent therapy after acute myocardial infarction: results from the OMEGA study. Clin Res Cardiol Off J Ger Card Soc 102:671-677. doi:10.1007/s00392-013-0581-2

8. Desch S, Siegemund A, Scholz U, Adam N, Eitel I, de Waha S, Furnau G, Lurz P, Wetzel S, Schuler G, Thiele H (2012) Platelet inhibition and GP IIb/IIIa receptor occupancy by intracoronary versus intravenous bolus administration of abciximab in patients with ST-elevation myocardial infarction. Clin Res Cardiol Off J Ger Card Soc 101:117-124. doi:10.1007/s00392-011-0372-6

9. Zusman O, Amit G, Gilutz H, Zahger D (2012) The significance of new onset atrial fibrillation complicating acute myocardial infarction. Clin Res Cardiol Off J Ger Card Soc 101:17-22. doi:10.1007/s00392-011-0357-5

10. Zeymer U, Arntz HR, Mark B, Fichtlscherer S, Werner G, Scholler R, Zahn R, Diller F, Darius H, Dill T, Huber K (2012) Efficacy and safety of a high loading dose of clopidogrel administered prehospitally to improve primary percutaneous coronary intervention in acute myocardial infarction: the randomized CIPAMI trial. Clin Res Cardiol Off J Ger Card Soc 101:305-312. doi:10.1007/s00392-011-0393-1 
11. Olivier CB, Schnabel K, Brandt C, Weik P, Olschewski M, Zhou Q, Bode C, Diehl P, Moser M (2014) A high ratio of ADP-TRAP induced platelet aggregation is associated more strongly with increased mortality after coronary stent implantation than high conventional ADP induced aggregation alone. Clin Res Cardiol Off J Ger Card Soc 103:968-975. doi:10.1007/s00392-014-0737-8

12. Steg PG, James S, Harrington RA, Ardissino D, Becker RC, Cannon CP, Emanuelsson H, Finkelstein A, Husted S, Katus H, Kilhamn J, Olofsson S, Storey RF, Weaver WD, Wallentin L (2010) Ticagrelor versus clopidogrel in patients with ST-elevation acute coronary syndromes intended for reperfusion with primary percutaneous coronary intervention: a platelet inhibition and patient outcomes (PLATO) trial subgroup analysis. Circulation 122:2131-2141. doi:10.1161/circulationaha.109.927582

13. Meine TJ, Roe MT, Chen AY, Patel MR, Washam JB, Ohman EM, Peacock WF, Pollack CV Jr, Gibler WB, Peterson ED (2005) Association of intravenous morphine use and outcomes in acute coronary syndromes: results from the CRUSADE quality improvement initiative. Am Heart J 149:1043-1049. doi:10.1016/ j.ahj.2005.02.010

14. Nimmo WS, Heading RC, Wilson J, Tothill P, Prescott LF (1975) Inhibition of gastric emptying and drug absorption by narcotic analgesics. Br J Clin Pharmacol 2:509-513

15. Hobl EL, Stimpfl T, Ebner J, Schoergenhofer C, Derhaschnig U, Sunder-Plassmann R, Jilma-Stohlawetz P, Mannhalter C, Posch M, Jilma B (2014) Morphine decreases clopidogrel concentrations and effects: a randomized, double-blind, placebo-controlled trial. J Am Coll Cardiol 63:630-635. doi:10.1016/j.jacc.2013.10. 068

16. Abell LM, Liu EC (2011) Dissecting the activation of thienopyridines by cytochromes P450 using a pharmacodynamic assay in vitro. J Pharmacol Exp Ther 339:589-596. doi:10.1124/ jpet.111.184895

17. Farid NA, Kurihara A, Wrighton SA (2010) Metabolism and disposition of the thienopyridine antiplatelet drugs ticlopidine, clopidogrel, and prasugrel in humans. J Clin Pharmacol 50:126-142. doi:10.1177/0091270009343005

18. Dansette PM, Rosi J, Debernardi J, Bertho G, Mansuy D (2012) Metabolic activation of prasugrel: nature of the two competitive pathways resulting in the opening of its thiophene ring. Chem Res Toxicol 25:1058-1065. doi:10.1021/tx3000279

19. Braun OO, Angiolillo DJ, Ferreiro JL, Jakubowski JA, Winters KJ, Effron MB, Duvvuru S, Costigan TM, Sundseth S, Walker JR, Saucedo JF, Kleiman NS, Varenhorst C (2013) Enhanced active metabolite generation and platelet inhibition with prasugrel compared to clopidogrel regardless of genotype in thienopyridine metabolic pathways. Thromb Haemost 110:1223-1231. doi:10. 1160/th13-03-0263

20. Siller-Matula JM, Krumphuber J, Jilma B (2010) Pharmacokinetic, pharmacodynamic and clinical profile of novel antiplatelet drugs targeting vascular diseases. Br J Pharmacol 159:502-517. doi:10.1111/j.1476-5381.2009.00555.x

21. Brandt JT, Payne CD, Wiviott SD, Weerakkody G, Farid NA, Small DS, Jakubowski JA, Naganuma H, Winters KJ (2007) A comparison of prasugrel and clopidogrel loading doses on platelet function: magnitude of platelet inhibition is related to active metabolite formation. Am Heart J 153(66):e9-e16. doi:10.1016/j. ahj.2006.10.010

22. Siller-Matula JM, Trenk D, Schror K, Gawaz M, Kristensen SD, Storey RF, Huber K (2013) Response variability to P2Y12 receptor inhibitors: expectations and reality. JACC Cardiovasc interv 6:1111-1128. doi:10.1016/j.jcin.2013.06.011

23. Aradi D, Komocsi A, Vorobcsuk A, Serebruany VL (2013) Impact of clopidogrel and potent P2Y 12 -inhibitors on mortality and stroke in patients with acute coronary syndrome or undergoing percutaneous coronary intervention: a systematic review and meta-analysis. Thromb Haemost 109:93-101. doi:10.1160/ th12-06-0377

24. Saucedo JF, Angiolillo DJ, DeRaad R, Frelinger AL 3rd, Gurbel PA, Costigan TM, Jakubowski JA, Ojeh CK, Duvvuru S, Effron MB (2013) Decrease in high on-treatment platelet reactivity (HPR) prevalence on switching from clopidogrel to prasugrel: insights from the switching anti-platelet (SWAP) study. Thromb Haemost 109:347-355. doi:10.1160/th12-06-0378

25. Gurbel PA, Bliden KP, Butler K, Tantry US, Gesheff T, Wei C, Teng R, Antonino MJ, Patil SB, Karunakaran A, Kereiakes DJ, Parris C, Purdy D, Wilson V, Ledley GS, Storey RF (2009) Randomized double-blind assessment of the ONSET and OFFSET of the antiplatelet effects of ticagrelor versus clopidogrel in patients with stable coronary artery disease: the ONSET/OFFSET study. Circulation 120:2577-2585. doi:10.1161/circulationaha. 109.912550

26. Siller-Matula JM, Christ G, Lang IM, Delle-Karth G, Huber K, Jilma B (2010) Multiple electrode aggregometry predicts stent thrombosis better than the vasodilator-stimulated phosphoprotein phosphorylation assay. J Thromb Haemost 8:351-359. doi:10. 1111/j.1538-7836.2009.03699.x

27. Fuchs I, Frossard M, Spiel A, Riedmuller E, Laggner AN, Jilma B (2006) Platelet function in patients with acute coronary syndrome (ACS) predicts recurrent ACS. J Thromb Haemost 4:2547-2552. doi:10.1111/j.1538-7836.2006.02239.x

28. Schwarz UR, Geiger J, Walter U, Eigenthaler M (1999) Flow cytometry analysis of intracellular VASP phosphorylation for the assessment of activating and inhibitory signal transduction pathways in human platelets-definition and detection of ticlopidine/clopidogrel effects. Thromb Haemost 82:1145-1152

29. Spiel AO, Derhaschnig U, Schwameis M, Bartko J, Siller-Matula JM, Jilma B (2012) Effects of prasugrel on platelet inhibition during systemic endotoxaemia: a randomized controlled trial. Clin Sci 123:591-600. doi:10.1042/cs20120194 London, England: 1979

30. Spiel AO, Bartko J, Schwameis M, Firbas C, Siller-Matula J, Schuetz M, Weigl M, Jilma B (2011) Increased platelet aggregation and in vivo platelet activation after granulocyte colonystimulating factor administration. A randomised controlled trial. Thromb Haemost 105:655-662. doi:10.1160/th10-08-0530

31. Spiel AO, Siller-Matula J, Firbas C, Leitner JM, Russmueller G, Jilma B (2010) Single dose granulocyte colony-stimulating factor markedly enhances shear-dependent platelet function in humans. Platelets 21:464-469. doi:10.3109/09537104.2010.485255

32. Farid NA, McIntosh M, Garofolo F, Wong E, Shwajch A, Kennedy M, Young M, Sarkar P, Kawabata K, Takahashi M, Pang H (2007) Determination of the active and inactive metabolites of prasugrel in human plasma by liquid chromatography/tandem mass spectrometry. Rapid Commun Mass Spectrom 21:169-179. doi: $10.1002 / \mathrm{rcm} .2813$

33. Huang SM, Temple R, Throckmorton DC, Lesko LJ (2007) Drug interaction studies: study design, data analysis, and implications for dosing and labeling. Clin Pharmacol Ther 81:298-304. doi:10.1038/sj.clpt.6100054

34. Sugidachi A, Ogawa T, Kurihara A, Hagihara K, Jakubowski JA, Hashimoto M, Niitsu Y, Asai F (2007) The greater in vivo antiplatelet effects of prasugrel as compared to clopidogrel reflect more efficient generation of its active metabolite with similar antiplatelet activity to that of clopidogrel's active metabolite. J Thromb Haemost 5:1545-1551. doi:10.1111/j.1538-7836.2007. 02598.x

35. Bochner F, Lloyd JV (1995) Aspirin for myocardial infarction. Clinical pharmacokinetic considerations. Clin Pharmacokinet $28: 433-438$ 